\title{
No exílio, contra o isolamento: intelectuais comunistas, frentismo e questão democrática nos anos 1970
}

\author{
MARCOS NAPOLITANO ${ }^{I}$
}

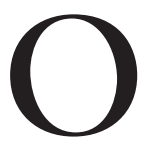

LUGAR DO exílio na história cultural do regime militar brasileiro ainda precisa ser mais aprofundado como objeto historiográfico. Comparado com os estudos sobre outros aspectos do período, o tema do exílio é um dos menos estudados. À parte dos inúmeros livros que contam as memórias dos exilados, os trabalhos monográficos podem ser considerados exíguos (Rollemberg, 1999; Cruz, 2010; Muzart, 2008). Podemos nos perguntar se isso não seria o reflexo da própria experiência histórica em seu sentido global - humana, cultural e política - do exílio na história recente do Brasil. Em outras palavras, o centro dinâmico da experiência do autoritarismo dos anos 1960 e 1970, que produziu milhares de cidadãos brasileiros exilados, em que pese seu drama humano individual, pode não ter tido sua dinâmica central no plano cultural. $\mathrm{O}$ caso brasileiro, visto em perspectiva, aponta para outra dimensão do lugar do exílio, se compararmos o mesmo tema na história recente do Chile e da Argentina, por exemplo (Silva, 2009). Mas essa é apenas uma hipótese aproximativa, pois não seria surpresa se o aprofundamento do estudo sobre o exílio dos militantes brasileiros revelasse novas articulações entre as dinâmicas da resistência cultural interna e as reflexões, agendas e temas produzidos pelos exilados. Os estudos disponíveis já apontam nesse sentido, mapeando a experiência do exílio, forçado ou voluntário, em produções individuais na literatura, no teatro e no cinema (Cardoso, 2008), bem como a importância do exílio para certos temas da política brasileira, como a Anistia (Rollemberg, 1999) e o desgaste do regime militar no plano diplomático (Green, 2010).

Neste artigo vou focar as implicações do exílio europeu, particularmente o exílio parisiense para o debate interno do Partido Comunista Brasileiro (PCB), que, por sua vez, teve consequências diretas na leitura sobre a realidade brasileira produzida pelos comunistas, além de apontar para um novo protagonismo do intelectual dentro do Partido. O período escolhido, 1973 a 1980, corresponde à fase de acirramento da experiência do exílio político dos militantes de esquerda na Europa, particularmente em Paris, com a chegada de cerca de 800 novos exilados vindos sobretudo do Chile pós-golpe de Estado (Hildebrando, 2001). 


\section{$\mathrm{PCB}$, intelectuais e cultura}

A história do PCB em muitos momentos se confunde com a história da formação cultural brasileira no século XX. Outros grupos de esquerda, como os trotskistas e socialistas, podem até ter desenvolvido um senso crítico mais apurado para captar as contradições sociais, políticas e, sobretudo, econômicas, que marcaram o desenvolvimento capitalista brasileiro e a traumática "modernização conservadora" imposta pelas elites ao longo do século XX, questionando os dogmáticos esquemáticos que o PCB muitas vezes mobilizou para compreender o Brasil. Mas é inegável que o PCB ocupa um lugar destacado na produção de uma cultura e de uma estética canônica, em grande parte incorporada pelo que chamamos de "brasilidade" (Ridenti, 2010). Pode-se afirmar que há uma cultura política comunista, entendida como um "conjunto de valores, tradições, práticas e representações políticas partilhado por determinado grupo" (Motta, 2013 , p.17). Essa cultura política comunista era baseada no internacionalismo, o anti-imperialismo (que abriu espaço para um tipo de nacionalismo progressista de esquerda, sobretudo nos países do Terceiro Mundo), o culto ao modelo bolchevique-soviético. No caso brasileiro, conforme Rodrigo Sá Motta, os comunistas agregaram alguns traços da cultura política local, como a tendência à conciliação política, que ajudou a ampliar o leque de alianças políticas, nem sempre muito fecundas para a esquerda, na busca de frentes nacionalistas (ibidem, p.31). No período do regime militar brasileiro, a tendência a um amplo frentismo político foi a força e a fraqueza do PCB. Foi justamente no exílio europeu que essa tendência se aprofundou e ganhou novas elaborações teóricas, como mostraremos mais adiante.

A questão da "brasilidade", a meu ver, é uma categoria fundamental para explicar boa parte da tradição cultural comunista-pecebista. Essa categoria ideológica difusa, disputada à esquerda e à direita desde ao menos os anos 1930, pautou a busca de uma identidade nacional própria que, na visão dos nacionalistas de diversos matizes, deveria temperar os efeitos deletérios do desenvolvimento capitalista. Se para a direita intelectual tratava-se de defender a tradição e a especificidade da nação como aglutinadora da sociedade em torno do Estado nacional autoritário e tutelar (Beired, 1999), para a esquerda, a brasilidade era a afirmação de uma identidade nacional-popular e de um idioma cultural comum a várias classes sociais que pudesse enfrentar o imperialismo e seus aliados internos. Para a direita, a afirmação da brasilidade era a garantia da superação dos conflitos sociais e a aceitação das hierarquias naturais da sociedade, pela idealização dos "de baixo". Para a esquerda, a brasilidade era a linguagem que deveria selar a aliança de classes e canalizar os conflitos sociais para o enfrentamento do imperialismo e do fascismo. Nessa chave é que se desenvolverá uma rica cultura comunista, cujas bases foram lançadas junto com a fundação do PCB em 1922, ampliando sua influência no debate cultural brasileiro a partir do final da Segunda Guerra Mundial. Ao término do conflito, capitaneado pelo protagonismo do 
comunismo internacional na luta contra o nazifascismo, o comunismo exerceu forte atração sobre intelectuais e artistas de formação progressista e humanista. Mesmo nos anos da guerra fria, a partir de 1947, o comunismo se manteve importante como referência intelectual, em que pesem a antipropaganda ocidental e o impacto das revelações dos crimes de Josef Stalin no XX Congresso do Partido Comunista da União Soviética, em 1956.

Apesar da forte atração que o comunismo e o PCB exerceram sobre artistas e intelectuais brasileiros, a relação desses com o Partido nunca foi isenta de conflitos. Não se trata de aderir à visão dos intelectuais como vítimas do autoritarismo partidário ou como criadores reprimidos pela máquina burocrática, reféns dos seus próprios valores bolcheviques. Em muitos casos, o Partido ajudou a consolidar a posição dos intelectuais na sociedade e a divulgar e legitimar as suas obras, ao mesmo tempo em que a adesão intelectual legitimava o Partido como entidade política junto à sociedade como um todo (Ridenti, 2010). Mas é inegável que os intelectuais sempre tiveram uma posição secundária na máquina partidária e nunca foram os formuladores centrais de sua política. Até aí, poder-se-ia argumentar, nenhuma novidade em relação a outros partidos comunistas do mundo. Mas também não podemos desprezar as nuanças do caso brasileiro. Aqui nunca tivemos o fenômeno da "ilustração operária" que marcou o Partido Comunista Chileno, por exemplo, nem a relação orgânica que marcou a ação intelectual e artística dos quadros do Partido Comunista Italiano (Dalmas, 2012; Ajello, 1997). Entretanto, no caso brasileiro, arrisco dizer que o aspecto mais paradoxal da história cultural do PCB é a disparidade entre a força do partido, sempre secundária na cena política e social (até pela forte e constante repressão policial), e a forte e, em alguns momentos, até mesmo hegemônica presença dos artistas e intelectuais do Partido na vida cultural brasileira.

Acredito que em parte esse aparente paradoxo se explique pelo lugar que os intelectuais tiveram dentro do PCB. Desprestigiados no início dos anos 1930, com o chamado "obreirismo" que expurgou muitos intelectuais em prol da ascensão dos operários, os intelectuais e artistas comunistas e simpatizantes continuavam tentando traduzir em formas estéticas e formulações intelectuais os valores ideológicos do comunismo (Feijó, 2001). Essa militância cultural se desenvolveu de forma mais ou menos livre até meados dos anos 1940. Com a guerra fria, a relação com intelectuais mudou. Entre 1947 e 1954, aproximadamente, os dirigentes partidários assumiram a tarefa de conduzir os intelectuais de maneira mais rígida, informados pelo jdanovismo, também conhecido como "realismo socialista" (Moraes, 1994). Na óptica partidária, para enfrentar a máquina de propaganda capitalista comandada pela forte indústria cultural estadunidense, era preciso um comando centralizado e uma unidade de ação no plano cultural. O velho controle leninista sobre os intelectuais exacerbou-se, sob o mote de transformá-los em “engenheiros das almas”. No Brasil, a fase do realismo socialista foi o único período que, a rigor, foi marcada por uma efetiva 
política cultural partidária, estabelecendo conexões diretas entre os dirigentes e os intelectuais que perderam sua autonomia (Moraes, 1994; Rubim, 1986). A literatura e a música erudita foram particularmente acompanhadas de perto pela direção do PCB e seus órgãos culturais, como a revista Fundamentos, tornando-se áreas de conflito com outras ideologias e matrizes estéticas (Egg, 2004). O realismo como linguagem, as mazelas sociais como temas, o otimismo revolucionário como inspiração criadora e a obra como veículo de comunicação com as massas foram os eixos desta política cultural.

O fim do jdanovismo, braço cultural do stalinismo em sua última fase, foi acompanhado de um debate interno sobre o lugar do PCB na política brasileira, culminando em uma autocrítica sobre seu isolamento chancelado pelo documento conhecido como "Manifesto de Agosto de 1950". Neste, o PCB apostava na revolução camponesa e prescindia de alianças sociais com outras forças progressistas e nacionalistas, em um momento de afirmação de experiências políticas que envolviam a participação de massas e a alavancagem do desenvolvimento industrial. O impacto da morte de Getulio Vargas, alma mater dessa política, sobre as massas operárias e a aliança entre militantes comunistas e não comunistas nas lutas sociais, muitas vezes à revelia da política oficial do Partido, inspiraram uma grande revisão política, materializada na "Declaração de Março" de 1958. Esse documento marcou o nascimento da chamada "Nova Política", que passou a incorporar a questão democrática, ainda que em um primeiro momento subordinada à "questão nacional", ou seja, a afirmação de um desenvolvimento capitalista autônomo contra o imperialismo. A partir daí, o PCB definiu a revolução brasileira como sendo "democrática, nacional, antifeudal e anti-imperialista", abrindo a possibilidade de novas alianças com outras classes sociais e grupos políticos. Essa abertura fez que se iniciasse uma fase de grande prestígio e poder de atração do Partido, voltando a aglutinar muitos intelectuais até o golpe militar de 1964. A renovada sedução partidária sobre artistas e intelectuais será a base da chamada "corrente da hegemonia" nas lutas culturais até o final dos anos 1970, fazendo que a cultura política e a produção cultural do PCB sobrevivessem à dura repressão imposta pelos militares no plano político.

Os quadros culturais do PCB se mantiveram fiéis ao princípio da defesa da cultura nacional-popular, vista como mediação construída pelo intelectual engajado entre o regional e o cosmopolita e como linguagem simbólica comum que deveria expressar a aliança de classes na defesa na nação contra o imperialismo e contra a "ditadura fascista". Os comunistas defendiam a ocupação de todos os espaços possíveis dentro do sistema, negociando até certo ponto o próprio conteúdo de suas ideias, materializadas em peças de teatro, filmes, canções e novelas. Ao longo dos anos 1970, os agentes culturais ligados ao "partidão" foram fundamentais na consagração de um conteúdo peculiar da indústria cultural brasileira, sobretudo no cinema, na TV e na música popular, de ampla aceitação junto ao público consumidor de classe média. Esses conteúdos híbridos mes- 
clavam elementos do nacionalismo, populismo, folclorismo, realismo socialista, temperados por uma estética narrativa e realista, herdada, sobretudo, da cultura europeia do século XIX. Por outro lado, não descartavam elementos herdados do "projeto moderno brasileiro". ${ }^{1}$

O PCB reiterou sua linha frentista e civilista no VI Congresso realizado em dezembro de 1967, o que não quer dizer que essa estratégia geral tenha sido executada de maneira linear, homogênea e sem conflitos internos. A começar pela saída de importantes líderes comunistas que aderiram à luta armada no final dos anos 1960, como Carlos Marighela e Jacob Gorender. A definição do regime militar brasileiro como uma "ditadura fascista", sugerida pelo Comitê Estadual da Guanabara em 1970 e ratificada pelo Comitê Central em 1973 e 1977, reforçou ainda mais as posições que assumiam a "questão democrática" como eixo da resistência frentista. ${ }^{2}$ Alguns setores do Partido, como o secretário-geral Luis Carlos Prestes, questionaram essa linha de ação, defendendo uma frente de esquerda mais restrita, sem abrir mão da identidade socialista e da vocação "revolucionária" do Partido (Prestes, 1980). Após a Anistia de 1979, a luta interna se acirrou entre "renovadores" e "ortodoxos", mas o processo partidário vivenciado entre 1980 e 1983 acabou por isolar as duas correntes favorecendo uma nova camada dirigente que reiterou as alianças amplas em nome da democracia, mas sem a renovação das estruturas partidárias e das concepções teóricas defendidas pelos "renovadores" (Tafarello, 2009, p.55-9). A corrente "renovadora", muitas vezes chamada de "Eurocomunista" era liderada por Armênio Guedes (Vaia, 2013, p.123), e integrada por Luiz Werneck Vianna, Leandro Konder, Carlos Nelson Coutinho, Aloysio Nunes Ferreira, entre outros. Sob influência de Gramsci, tentaram redimensionar o papel do Partido Comunista Brasileiro na redemocratização, desvinculando a democracia política do capitalismo, aceitando-a como "valor universal". Além de defender alianças políticas amplas, defendia uma renovação teórica (criticando o "etapismo" e o economicismo) e maior participação da militância nas decisões do Partido. Entre março de 1980 e julho de 1981, essa corrente hegemonizou o novo semanário oficial do Partido, Voz da Unidade, dispersando-se a partir de 1983. Antes disso, em 1980, o lendário Luiz Carlos Prestes perdeu o comando do PCB para Giocondo Dias, mas isso não significou, necessariamente, a afirmação dos eurocomunistas na hegemonia partidária. O que acabou predominando foi um aliancismo pragmático que fez que o PCB ficasse refém dos termos impostos pelos liberais-moderados no processo de transição para o governo civil.

Vejamos como a experiência do exílio, sobretudo na capital francesa, foi fundamental para a afirmação dessa corrente.

\section{A esquerda brasileira em Paris}

A cidade de Paris foi um dos destinos privilegiados de todos os exilados políticos do mundo, desde o começo do século XX. Capital cultural do Ocidente, "noiva" de todas as revoluções, Paris fascinava o mundo intelectual e ofere- 
cia, ainda que precariamente, redes de sociabilidade que garantiam sobrevivência física e espiritual para o exilado. Mas Paris não foi o único, nem o primeiro, destino privilegiado da intelectualidade ou da militância de esquerda brasileira dispersada pelo golpe de $1964 .{ }^{3}$ Outros países que à época afirmavam suas imagens progressistas ou revolucionárias aos olhos do mundo diplomático, como o México, a Argélia, a Suécia ou mesmo o Chile da segunda metade dos anos 1960 e do governo Allende, receberam muitos dissidentes do regime militar. $\mathrm{Na}$ Europa, os exilados brasileiros se concentravam na França e na Itália, com alguma incidência na Suécia e na Alemanha. Nos anos 1970, havia ainda um núcleo comunista mais ligado ao lendário líder Luis Carlos Prestes em Moscou. No caso de Paris, a cidade foi o destino de maior parte da esquerda armada no exílio, sobretudo depois do golpe militar que acabou com o governo da Unidade Popular chilena em setembro de 1973. Conforme Maud Chirio (2006, p.78) o número de exilados políticos brasileiros em Paris oscilou entre 1.000 e 2.000 pessoas, entre 1964 e 1979, apesar da população brasileira em Paris ser de cerca de 7.000, em meados dos anos 1980.

Essa pequena, mas barulhenta, comunidade de exilados em Paris constituiu-se como um microcosmo que reproduziu as tensões políticas e cisões da esquerda em fase de derrota e refluxo. ${ }^{4}$ Conforme Luis Hildebrando (2014), a esquerda brasileira em Paris se dividia em dois grandes ramos: de um lado, o bloco composto pelo PCB, católicos de esquerda, Grupo Debate, socialistas terceiro-mundistas, unidos na crítica à luta armada e ao foquismo inspirado na guerrilha Cubana; de outro, grupos de esquerda que ainda acreditavam na via armada imediata para "derrubar" a ditadura (maoístas, sobreviventes da Ação Libertadora Nacional, Vanguarda Popular Revolucionária, entre outros). Esses tinham apoio na famosa revista Les Temps Modernes, enquanto os primeiros eram apoiados pelo Partido Comunista Francês e suas redes sociais e sindicais.

Apesar das redes de apoio, sobretudo com os grupos de esquerda franceses afinados com as diversas linhas dos grupos brasileiros no exílio, o militantismo era exclusivamente brasileiro, sem articulação efetiva com militantes latino-americanos ou franceses. Havia pouca relação orgânica com partidos de esquerda franceses. Para Luis Hildebrando, o militantismo no exílio teve duas fases. A primeira foi a fase da "Denúncia" (1968-1971), marcada pela campanha contra as torturas e mortes de militantes, seguida da luta militante pela Anistia (1975). Os Comitês de Denúncia que se organizaram para expor a violência e a tortura da ditadura brasileira agregaram grande apoio intelectual e capital simbólico de personalidades europeias, o que não significava uma efetiva articulação ou tutela política. A Association France-Amérique Latine, organização com base no eixo Paris-Lyon foi importante nessa fase. A historiadora Maud Chirio reforça essa visão, afirmando que apesar da ação articulada dos comitês de denúncia, as ações políticas no exílio obedeciam a uma dinâmica própria dos grupos aos quais pertenciam os exilados. Em outras palavras, não havia conexões orgânicas 


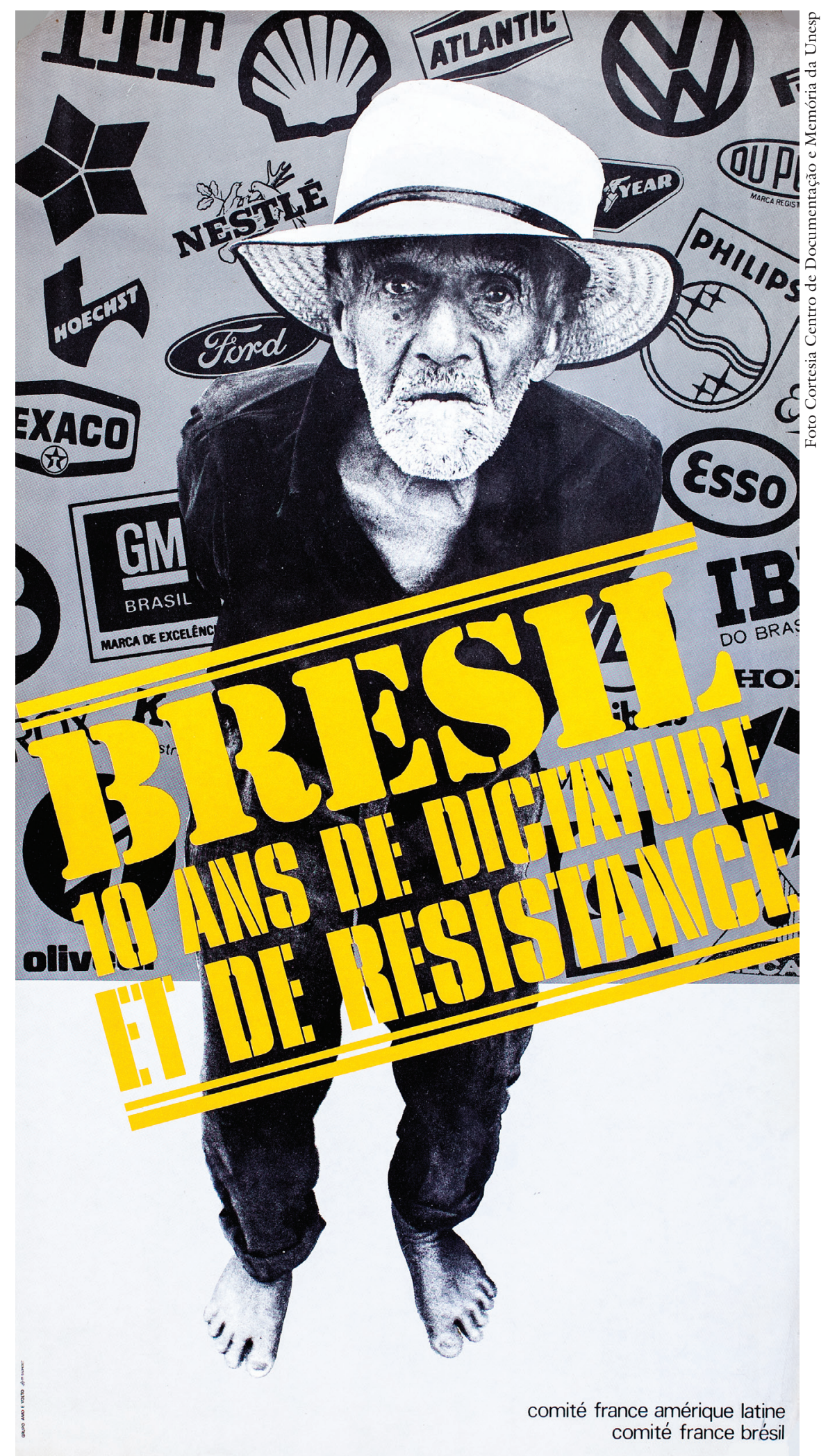

Cartaz francês de 1974 denuncia a violação dos direitos humanos no Brasil. 
e determinantes entre si ou entre os exilados e os militantes do país de origem, em que pesem eventuais simpatias ideológicas e redes de solidariedade (Chirio, 2006, p.83).

Já para Denise Rollemberg, a pauta política do exílio foi mais ampla e articulada, incluindo: denúncia das violações de Direitos Humanos; análise de conjuntura e das políticas do regime (em tom de crítica ideológica); autocríticas e balanço da luta armada; campanha pela Anistia. Em muitos momentos, essa pauta foi mesclada, embora após 1977 as análises de conjuntura e a questão da anistia prevalecessem.

Os debates da esquerda exilada foram marcados por alguns temas de forte repercussão, inclusiva na resistência interna à ditadura. Em primeiro lugar, denunciar as torturas e assassinatos de militantes, ação que notabilizou sobretudo o jornal Front Bresilienne d'Information. Outro tema importante era compreender o caráter do regime e sua relação com o desenvolvimento capitalista e com a burguesia brasileira. Não menos importante, sobretudo após 1975, foi o tema da Anistia, que encontrava muito eco nos movimentos de esquerda que ainda atuavam no Brasil. ${ }^{5}$ Esse debate acumulado no exílio teria consequências para as reinserções dos exilados por ocasião da sua volta ao Brasil (1979-1980) e de sua inserção na cena política no período da transição democrática.

Mesmo depois da chegada da esquerda armada, avessa aos "reformistas do partidão", a força política mais estruturada no exílio parisiense era o PCB, contanto com o apoio logístico do PCF. O núcleo pecebista parisiense era capitaneado por Armênio Guedes, Zuleika Alambert, Luis Hildebrando e Ivan Alves, entre outros. A partir de 1975, depois do acirramento da repressão sobre o PCB no Brasil, Guedes, sob pseudônimo de Julio ou Feitosa, ficou responsável pela edição do jornal oficial do Partido, A Voz Operária. No mesmo ano, o Comitê Central do Partido, reorganizado, passou a funcionar no exílio. Na composição do novo CC, os militantes "renovadores" sediados na França e na Itália ganharam mais espaço, tensionando-se com o núcleo dirigente capitaneado por Prestes em Moscou.

Em outros países da Europa ocidental, jovens intelectuais ligados ao Partido alimentavam os debates intelectuais que dividiam os brasileiros de Paris: Carlos Nelson Coutinho (Itália), Leandro Konder, Milton Temer e Roberto Morena (Alemanha). Esses núcleos de exilados constituíam redes de debate, pautado pela redefinição de estratégias políticas e pelo exame da "realidade brasileira", publicando revistas como Études Bresiliennes (França) ou Informações (Alemanha Oriental).

Apesar dessas redes de debate e de alguns pontos em comum, como as denúncias das torturas e desaparecimentos praticados pelo regime militar, os grupos de exilados brasileiros em Paris se dividiam entre os "reformistas", cujo exemplo maior eram os pecebistas e os "porra-loucas" da esquerda armada radical. Ao menos era com esses termos que ambos os grupos se desqualificavam 
mutuamente. Os pecebistas eram acusados de "reformistas", enquanto a esquerda armada reservava para si a qualificação de "revolucionária". Por outro lado, os comunistas consideravam os revolucionários como "porra-loucas" sectários que não tinham capacidade de compreensão da realidade política nacional e da necessidade de alianças amplas para derrotar a ditadura. Até 1975, esses dois grupos reproduziram as dissidências que já se acumulavam desde o golpe militar e foram acirradas pelo desencadeamento efetivo da luta armada, em 1967. A esquerda armada no exílio era maior em número de exilados, porém mais dividida em inúmeras facções, como os herdeiros da ALN, da VPR, do MR 8, entre outros grupos. Paradoxalmente, com a virtual destruição dessas organizações armadas em território brasileiro, as tensões entre elas e entre os grupos de esquerda que rejeitavam a luta armada se potencializam no exílio, tendência particularmente forte no cenário parisiense (Chirio, 2006, p.86).

Em Paris o núcleo comunista assumia a luta civil, o voto "útil” na oposição à ditadura brasileira (no caso, o Movimento Democrático Brasileiro) e a ação de massa como o melhor meio para combater a ditadura. Nesse sentido, reproduzia os termos do polêmico Manifesto do Comitê Estadual do PCB na Guanabara (1970), não por acaso, redigido pelo mesmo grupo de tinha Armênio Guedes como referência. Nesse Manifesto, defendia-se o voto no MDB, em apoio aos candidatos Nelson Carneiro e Danton Jobim, e condenava-se a luta armada. Portanto, o clima do Eurocomunismo e a rejeição de alguns partidos comunistas importantes como o PCE e o PCI à via insurrecional armada e à "ditadura do proletariado" não foram a causa da guinada democrática desse grupo. Quanto muito, lhe deu mais argumentos teóricos e mais força política no debate interno, alçando alguns intelectuais exilados a um novo lugar dentro do debate partidário.

\section{O exílio entre a política nacional e internacional}

Se a política internacional (notadamente as vicissitudes e debates da esquerda europeia) acirrava as divisões entre "reformistas" e "guerrilheiros", as dinâmicas internas da resistência à ditadura na sociedade brasileira possibilitavam não apenas a quebra de gelo, mas certa agenda comum de debates entre os reformistas e revolucionários do exílio. As tensões entre o "Grupão" (capitaneado pelo PCB) e os revolucionários foram particularmente fortes entre 1973 e 1975 , enquanto os sinais de uma nova conjuntura política interna chegavam do Brasil. A partir daí, as dinâmicas da política interna brasileira e da resistência ao regime possibilitaram, por outro lado, a construção de uma agenda comum e uma pauta comum de lutas. A partir de 1975, os temas da Anistia e da redemocratização ancorada em movimentos de massa deram certa hegemonia ao "Grupão", obrigando os micropartidos da esquerda armada a encarar o dilema do frentismo e o "combate democrático" com outras forças (Chirio, 2006).

O novo olhar para a questão democrática dos comunistas exilados na Europa ocidental encontrava eco também nas novas formas de resistência que se 
afirmavam na sociedade brasileira, sobretudo depois da derrota definitiva da luta armada, o que ocorreu por volta de 1973. O tema da democracia ganhava nova força, em que pesem as várias leituras que existiam sobre esse conceito entre os opositores do regime militar. Em 1978, a "questão democrática" ganha uma elaboração oficial do Comitê Central do PCB no exílio, sinal de que os frentistas e renovadores tinham cada vez mais força no debate interno:

Participando ativamente da luta unitária pelas liberdades democráticas, os comunistas reconhecem que não são idênticas as concepções de democracia que circulam, explicita ou implicitamente, entre as diversas correntes de oposição [...] sem ocultar nossa aspiração final ao socialismo, que compreende a mais ampla e profunda democracia, hoje nos empenhamos para que tais diferenças de concepções não impeçam nem dificultem a unidade política de todas as forças que lutam ou podem lutar na implantação de um regime democrático. $\mathrm{Na}$ atual situação, a prioridade deve ser concedida à luta pela conquista das liberdades democráticas. (Resolução CC, novembro 1978 in VV.AA, 1980, p.29l)

No plano internacional europeu, o Eurocomunismo que agitava o debate nos PC europeus entre 1970 e $1976,{ }^{6}$ bem como o tema do "Programa Comum" das esquerdas francesas tiveram forte impacto no debate e nas formulações do grupo pecebista de Paris. O mesmo problema da democracia e do aliancismo era colocado pelos grandes partidos comunistas europeus - PCF, PCE e PCI, obviamente em outro contexto social, cultural e político. O golpe no Chile terá forte impacto nesse debate, adensando a crítica dos eurocomunistas às opções mais sectárias e radicais, reforçando a tese da unidade das esquerdas diante da ameaça da direita. Mas essas não aceitavam prontamente a derrota militar e política da revolução armada. Mesmo com o desastre chileno, a esquerda armada no exílio permanecia fiel às opções, ainda que os grupos desenvolvessem entre 1973 e 1976 autocríticas formais que, na prática, congelavam a opção armada e aderiam à "política de massas" para combater a ditadura.

Dentre os vários aspectos da experiência dos comunistas no exílio, o importante neste texto é destacar que houve a afirmação de um grupo partidário que tentou atuar como intelectuais "autônomos", ainda que fieis às estruturas partidárias e seus princípios éticos-políticos centrais. Podemos dizer que a autonomia se manifestava de forma crescente, em formulações que nem sempre reverberava as decisões da cúpula partidária e as posições dos líderes históricos como Prestes.

No contexto da abertura, as posições do núcleo europeu-ocidental, do núcleo moscovita (capitaneado por Prestes) e do grupo dirigente que se manteve no Brasil caminhava para um dissenso, pois as leituras sobre o papel do Partido no contexto da transição não convergia. Enquanto os intelectuais influenciados pelo eurocomunismo apontavam para uma renovação do frentismo com outras forças progressistas, sem perder a capacidade de formular críticas originais ao "modelo brasileiro", o núcleo prestista estava mais disposto a se inserir nas 
disputas pela direção do vigoroso movimento social. Paralelamente, alguns dirigentes que se mantiveram na direção em solo brasileiro se encaminhavam para alianças mais pragmáticas e moderadas com a oposição liberal (Lima, 1995). Obviamente, na perspectiva histórica, não se trata de julgar erros e acertos políticos e purismos ideológicos nestas opções, mas analisar o resultado efetivo delas e seu impacto na crise e implosão do PCB ao longo dos anos 1980.

O fim do exílio aprofundou estas tensões internas do PCB. Giocondo Dias, da corrente pragmática, se afirmou como liderança partidária durante a crise de 1980, em meio à qual o núcleo prestista rompeu com o Partido e o próprio Prestes criticou duramente as novas diretrizes, acusando a direção partidária de abandonar "os objetivos revolucionários". Mas isso não significou maior espaço para os "renovadores eurocomunistas", como Guedes, Coutinho e Leandro Konder. As alianças pragmáticas com setores liberais acabaram dando o tom das discussões políticas do PCB. No Brasil, o grupo renovador tentou afirmar um novo espaço de debate, o jornal Voz da Unidade (fundado em março de 1980), mas os rumos da transição e o lugar do PCB nela acabaram por dispersar o grupo por volta de 1983, cujos membros mais destacados, como Leandro Konder e Carlos Nelson Coutinho, acabaram se afirmando como intelectuais autônomos dentro do "marxismo acadêmico".

\section{A abertura e a crise do frentismo comunista}

Esse aparente fracasso do projeto partidário dos "renovadores" que voltavam do exílio europeu não deve fazer que se subestime a importância do debate, sobretudo ao longo dos anos 1970. Naquele contexto, o novo protagonismo intelectual comunista com foco na questão democrática, reforçado a partir do exílio, frutificou em terras nativas. Mas, como vimos, não se pode dizer que ele nasceu a partir do nada na experiência do exílio europeu. Em grande parte, esse protagonismo se amparou na tentativa de afirmar e legitimar as bases da "Nova Política" construída a partir de 1958 como eixos da resistência política e cultural ao regime militar, em um momento no qual a opção da luta armada e a um novo criticismo intelectual de esquerda, protagonizados por outras correntes como os trotskistas e cristãos, ambos avessos às diretrizes do $\mathrm{PCB}$, pareciam implodir a "grande família comunista".

A partir do exílio na Europa ocidental, mas também contando com importantes conexões dentro do Brasil, formou-se uma corrente dentro do PCB marcada pelas seguintes perspectivas: 1) a reafirmação da aliança de classes com qualquer grupo opositor ao regime (estratégia do frentismo); 2) a revisão crítica do sentido da modernização capitalista e seus impactos sociais e culturais; 3 ) a afirmação do intelectual autônomo, ainda que alinhado aos valores partidários fundamentais, como agente fundamental, e não subordinado, da conquista da hegemonia.

$\mathrm{O}$ protagonismo intelectual aliado à defesa do frentismo contra o regime defendido pelos "renovadores" articulados a partir da Europa ocidental teve desdobramentos importantes também na área artístico-cultural, e talvez essa seja 
sua faceta menos estudada. Não por acaso, Armênio Guedes era ligado ao ainda pouco estudado "Comitê Cultural da Guanabara”, ao lado de Dias Gomes e Ferreira Gullar, um dos focos da resistência cultural comunista. Nos anos 1970, o protagonismo intelectual, artístico dentro da lógica frentista se ampliou. Miriam Hermeto destaca a ação político-cultural de um grupo de intelectuais por ela nomeada como "Grupo Casa Grande", a partir de 1975, com forte presença de comunistas e compagnons de route, nome tirado do local de reunião de vários intelectuais de oposição ao regime, o Teatro Casa Grande no Rio de Janeiro (Hermeto, 2010). Lugar de sociabilidade e de articulação de projetos intelectuais e estéticos, o "Grupo Casa Grande" organizou o "I Ciclo de Debate sobre Cultura Contemporânea", além dos três ciclos de debates sobre economia, eventos bastante concorridos e que apontavam para uma rearticulação do pensamento oposicionista na perspectiva frentista e civilista, após a derrota dos projetos de luta armada. O núcleo do grupo eram Paulo Pontes, Antônio Callado, Bete Mendes, Chico Buarque, Max Haus, Zuenir Ventura. Luiz Werneck Vianna, alinhado com a corrente dos renovadores eurocomunistas e que à época estava clandestino e vivia na casa de Paulo Pontes, era uma ponte com os intelectuais paulistas críticos à ortodoxia pecebista (Hermeto, 2010, p.79). Aliás, a trajetória de Luiz Werneck Vianna é muito elucidativa em relação ao circuito intelectual e cultural da oposição à ditadura. Carioca ligado ao PCB, Vianna passou uma temporada importante em São Paulo, entre 1971 e 1975, cursando o doutorado na USP, sob orientação de Francisco Weffort. Também circulou pelo Centro Brasileiro de Análise e Planejamento (Cebrap) e pela Unicamp, onde lecionava quando foi preso, em 1975. Depois de um interrogatório policial, fugiu para o Rio de Janeiro, onde se abrigou, "meio clandestino", na casa de Paulo Pontes e Bibi Ferreira, para concluir sua tese de doutorado, defendida na USP em 1976. Conforme Vianna (1976), enquanto Paulo Pontes escrevia a clássica peça Gota d'Água, em parceria com Chico Buarque, ele escrevia Liberalismo e sindicato no Brasil possibilitando uma ampla troca de ideias sobre o tema da modernização conservadora brasileira, o papel dos intelectuais divididos entre a cooptação e a resistência, bem como o contexto autoritário que se vivia, e suas contradições (Vianna in Rugai; Fernandes, 2006, p.169). Por outro lado, Vianna foi também uma espécie de articulador das oposições intelectuais de São Paulo - mais centrada no profissionalismo acadêmico-institucional - e do Rio de Janeiro - cuja tradição remete à sociabilidade cultural mais difusa, oscilando entre a boemia literária, o jornalismo, a burocracia oficial, as artes e as Universidades.

Assim, entre 1975 e 1980, esboçou-se dentro do PCB um frentismo político e intelectual de oposição, animado pelos comunistas no exílio da Europa ocidental. Os debates propostos pela revista editada pelo grupo comunista brasileiro em Paris, intitulada Études Bresiliennes, funcionavam como uma síntese das posições e debates propostos para aprofundar essa estratégia. Nela se discutia o significado da vitória eleitoral da oposição em 1974, as potencialidades do pro- 
grama do $\mathrm{MDB}$, a natureza do regime brasileiro (se uma variável do fascismo, como defendia o PCB ou autoritário, como defendiam os cebrapianos) e o real significado do desenvolvimento econômico impulsionado pelo regime. Apesar de só durar quatro números, a revista cobriu boa parte do período mais intenso destes debates, entre 1974 e 1978.

A partir das "elaborações do exílio" e do clima de debate proposto pelo eurocomunismo também surgiu uma tese de alto impacto no debate interno do PCB: "a democracia como valor universal" (Coutinho, 1979). ${ }^{7}$ Publicado em março de 1979 por Coutinho na revista Encontros com a Civilização Brasileira, o artigo de mesmo título foi discutido não apenas dentro do partido (desagradando a linha prestista que o considerava uma capitulação precipitada à democracia dita "burguesa"), mas também foi discutido à esquerda e à direita na conjuntura brasileira de então, marcada pelo aprofundamento da "abertura" e pela ampliação do movimento de massas pela democracia. É importante notar que a questão democrática dentro do $\mathrm{PCB}$, como vimos, não surgiu a partir desse texto de Coutinho. Desde, ao menos, a Declaração de Março de 1958, o lugar da democracia para os comunistas era um tema em debate permanente. Talvez, a novidade do texto seja assumir que não se tratava mais de pensar a democracia adjetivada ("burguesa"), nem como tática instrumental para o socialismo. O texto de Coutinho assumia a democracia como vocação histórica e tentava pensar qual seria o papel dos comunistas nesse plano, sugerindo que a democracia de massas poderia articular "hegemonia" e "pluralismo" no processo de construção de uma sociedade democrática e socialista. Em tal raciocínio, Coutinho negava tanto o totalitarismo de tradição stalinista (embora resgatasse o democratismo potencial nos textos de Lenin) quanto o pseudopluralismo da democracia liberal. No caso do Brasil, a junção entre democracia e socialismo era ainda mais desafiadora, pois ia de encontro à tradição "prussiana" das elites brasileiras e do processo de modernização que marcara a história republicana do Brasil. O texto foi publicado no agitado ano de 1979, marcado pelo aprofundamento da política de "abertura" do regime e pela reorganização do ambiente político proporcionada pela Lei de Anistia e pela reforma partidária que se preparava, sem falar no ressurgimento do movimento sindical e social. O texto parecia selar a rentreé de um PCB renovado na vida política brasileira, como epicentro de um frentismo calcado no mito da "sociedade civil democrática" contra o Estado autoritário.

Mas a história não foi bem assim. $\mathrm{O}$ frentismo não resistiria à criação retumbante do Partido dos Trabalhadores (PT), em fevereiro de 1980 (que se considerava o herdeiro mais combativo da tradição das lutas operárias e se pautava pela chamada "democracia de base"), e às dissidências internas entre renovadores e prestistas no comando do Partido em São Paulo e à ascensão do brizolismo no Rio de Janeiro. ${ }^{8}$

O Partido dos Trabalhadores no começo dos anos 1980 foi um polo de 
confronto dentro do campo das esquerdas, que acabou por alimentar as críticas ao PCB como um partido reformista e moderado, que já não poderia falar sozinho em nome dos movimentos sociais mais "autênticos". Se as cisões internas do PCB se incrementavam, boa parte da esquerda ex-armada se unificou em torno do PT, o que também não era garantia de unidade de ação partidária. Entretanto, o caráter ideologicamente vago e o pragmatismo da direção petista à época, favoreceram a entrada de diversas tendências que, bem ou mal, consolidaram a legenda como a nova força da esquerda brasileira. A crítica ao etapismo, ao nacionalismo (mesmo "de esquerda") e ao "centralismo democrático" tão caro à tradição pecebista unificava as diversas tendências petistas, de católicos a trotskistas.

As tensões crescentes entre PT e PCB, com leituras completamente diferentes sobre a "questão democrática" na transição da ditadura para um governo civil, impediram definitivamente a afirmação de uma frente de esquerda contra a ditadura, acalentada durante os anos de exílio, sobretudo pelo grupo parisiense do PCB. Internamente, o grupo parisiense/europeu tentou atuar no jornal $A$ Voz da Unidade, mas acabou tragado pelas diretrizes políticas do Partido a partir de 1983, que apostou na transição conservadora liderada por setores moderados do PMDB. A partir daí, tanto no aspecto cultural quanto no político, o PCB entrou em declínio, encerrando seu longo ciclo partidário em 1991.

No plano cultural (e artístico), esse debate também gerou polêmicas. Não por acaso, a hegemonia nas lutas culturais de esquerda também mudou de foco: o nacional-popular, pedra de toque da ação cultural do Partido desde os anos 1950, o realismo como linguagem fundamental da arte e o intelectual como formulador e mediador do idioma cultural comum da aliança de classes passaram por uma profunda crítica da nova esquerda intelectual petista (Napolitano, 2011). Esses elementos passaram a ser vistos como armadilhas ideológicas que conduziram ao desastre de 1964, ao reforço do conservadorismo estético e político e à fácil assimilação da arte engajada dos comunistas pela indústria cultural brasileira (Chaui, 1980). O que o golpe militar tentou, mas não conseguiu, ou seja, esvaziar a influência do PCB na cultura e na política brasileira, a errática transição democrática acabou logrando.

A volta dos exilados, adensados pelos longos e complexos debates ideológicos e de análise conjuntural, acabou por se diluir na nova realidade político-partidária criado pela reforma política de 1979. Se o exílio unificava certos temas, como a Anistia, a nova conjuntura apontava para uma divisão entre comunistas, trabalhistas (sobretudo da corrente brizolista) e petistas. Os debates acumulados no exílio comunista, que se encaminhavam para a defesa de uma frente antiautoritária, não resistiram aos tempos de abertura e às novas tensões do campo da oposição ao regime. O conceito de democracia surgido do contato com o eurocomunismo não encontrava eco no fundamentalismo democrático e basista do PT, que recusava qualquer frente que representasse um eventual 
recuo na pauta dos movimentos sociais. No caso do PCB, a aposta no frentismo progressista, dinamizado por reformulações no conceito de nação, povo e sociedade civil, bem como na leitura crítica dos efeitos da modernização capitalista, para além dos clichês dualistas herdados dos anos 1950, não foi suficiente para manter o Partido no protagonismo da transição com luz própria. Enquanto a esquerda se digladiava, a velha tradição de conciliação liberal-moderada conduzia a transição, mostrando que ainda era mais forte do que se pensava.

\section{Notas}

1 A expressão "projeto moderno brasileiro" é utilizada, normalmente, para designar o mainstream da arquitetura brasileira do século XX, inspirada em Le Corbusier. Aqui, utilizo a expressão de maneira mais livre para englobar o conjunto dialético, plural e dinâmico dos projetos estético-culturais voltados para a construção (ou desconstrução) identitária da modernidade brasileira, gestados entre 1922 e 1968.

2 Os documentos em questão: "Resolução Política do Comitê Estadual da Guanabara" (1970); "Por uma frente Patriótica contra o Fascismo" (1973); "Resolução Política do Comitê Central” (1977).

3 Entre 1964 e 1968, “poucos exilados” brasileiros: Juscelino Kubitschek, José Serra, Celso Furtado, Almino Afonso, Raul Ryff, Valdir Pires, Josué de Castro, entre outros. Em 1968 surge uma nova leva de exilados: Oscar Niemeyer, Márcio Moreira Alves, Fernando Perrone, Pierre Gervaiseau e Violeta Arraes.

4 A imprensa militante produzida pelos exilados é um termômetro desse debate. O mais longevo órgão de imprensa foi o jornal Debate, publicado pelo grupo homônimo, que defendia uma unidade revolucionária (Paris, 1970-1982, 40 números). Ainda havia o jornal Campanha, Brésil Bulletin, (CBA de Paris), e Brésil Socialiste da chamada "esquerda proletária” (APML, MR8, PO, 1975). Outro elemento importante no exílio foi a emergência do feminismo como tema com o surgimento do Comitê de Mulheres Brasileiras (1972, Chile) e o Grupo Brasileiro de Mulheres Revolucionárias (Rollemberg, 1999).

5 Em Paris, surgiu o Comitê Brasileiro de Anistia 10 set. 1974, Guy Aurenche - Assoc. Juristas Católicos. Luis Hildebrando cita a reunião na casa de Vitória Arraes em 1968, e o discurso de Terezinha Zerbini proferido na ocasião, que consagram a Anistia ponto em comum. Aliás, esse episódio nos coloca um outro problema e uma outra hipótese, a ser confirmada pelo aprofundamento das pesquisas, que é o papel mediador da esquerda católica nesse momento, para aproximar os grupos cindidos no exílio. Para a luta pela anistia no exílio, destaque-se ainda a importância das conexões italianas: Tribunal Bertrand Russell II, Roma 1974, e a Conferência Internacional pela Anistia, 28 a 30 de julho 1979, Roma (Rollemberg, 1999, p.233-48).

6 Enrico Berlinguer, líder do PCI, havia lançado o debate sobre o eurocomunismo no texto “A Questão Comunista" (1973), focado na reflexão sobre a "via Chilena” e as razões de sua derrota. A posição contra o PCURSS, defendendo o "compromisso histórico" (aliança com a Democracia Cristã) já havia sido lançada na Conferência Internacional dos PC em 1969, em Moscou. Nesses textos, o modelo leninista e soviético era profundamente questionado pelo líder do maior partido comunista do Ocidente.

7 Para um painel geral dos debates, ver Silveira (2013). 
$8 \mathrm{Um}$ dos documentos mais bem acabados dessa tentativa de articular um frentismo intelectual e político de oposição foi o programa do MDB para as eleições de 1974, elaborado por uma comissão de intelectuais cebrapianos (Fernando Henrique Cardoso, Francisco Weffort, Paul Singer, Luiz Werneck Vianna e Francisco Oliveira), a convite de Ulisses Guimarães. Esse frentismo reunia liberais de oposição, social-democratas e comunistas na releitura do papel do Estado e das classes sociais na modernização brasileira e seria objeto de crítica das forças que viam na transição política para a democracia um momento de refundação do Brasil, de "baixo para cima", prescindindo e criticando o papel histórico das elites e do Estado. Os circuitos e implicações dessa rede ainda estão por ser investigados em profundidade.

\section{Referências}

AJELLO, N. Intellettuali e PCI, 1944-1958 e Il lungo addio. Intellettuali e PCI dal 1958 al 1991. Roma; Bari: Laterza, 1997.

BEIRED, J. L. Sob o signo da Nova Ordem. Intelectuais autoritários no Brasil e na Argentina (1920-1940). São Paulo: Loyola; História Social - USP, 1999.

BRANDÃO, G. M. A esquerda positiva. As duas almas do Partido Comunista. São Paulo: Hucitec, 1997.

CARDOSO, M. Glauber Rocha et la tentation de l'exil (1972-1976). In: MUZART, I.; ROLLAND, D. (Org.) L'Exil brésilien en France: histoire et imaginaire. Paris: L'Harmattan, 2008. v.1, p.327-39.

CHAUÍ, M. Seminários. São Paulo: Brasiliense, 1980. (Col. “O nacional e o popular na cultura brasileira")

CHIRIO, M. Formes et dynamiques des mobilisations politiques des exilés brésiliens en France (1968-1979). Cahiers d'Amérique Latine, p.48-9, 2006.

COUTINHO, C. N. A democracia como valor universal. Encontros com a Civilização Brasileira, n.9, março 1979.

CRUZ, F. L. da. Frente brasileño de informaciones e campanha: os jornais de brasileiros exilados no Chile e na França (1968-1979). 2010. Dissertação (Mestrado em História Social) - Faculdade de Filosofia, Letras e Ciências Humanas, Universidade de São Paulo. São Paulo, 2010.

DALMAS, C. Frentismo cultural em prosa e verso: comparações, conexões e circulação das ideias entre comunistas brasileiros e chilenos (1935-1948). 2012. Tese (Doutorado em História Social) - Faculdade de Filosofia, Letras e Ciências Humanas, Universidade de São Paulo. São Paulo, 2012.

EGG, A. O debate no campo do nacionalismo musical no Brasil dos anos 1940 e 1950: o compositor Guerra Peixe. 2004. Dissertação (Mestrado em História) - Departamento de História, Universidade Federal do Paraná. Curitiba, 2004

FEIJÓ, M. O revolucionário cordial: Astrojildo Pereira e as origens de uma política cultural. São Paulo: Boitempo, 2001.

GREEN, J. Apesar de vocês: oposição à ditadura brasileira nos EUA. São Paulo: Cia. das Letras, 2010.

HERMETO, M. Olha a Gota que falta, Gota D'Água: um evento no campo artístico- 
-intelectual brasileiro (1975-1980). 2010. Tese (Doutorado em História) - Faculdade de Filosofia e Ciências Humanas, Universidade Federal de Minas Gerais. Belo Horizonte, 2010.

HILDEBRANDO, L. Crônicas de nossa época. São Paulo: Paz e Terra, 2001.

A campanha pela anistia em Paris. Disponível em: <http://novo.fpabramo.org.br/content/luiz-hildebrando-pereira-da-silva-campanha-pela-anistia-em-paris-1974-1979>. Acesso em: 17 fev. 2014.

KONDER, L. A democracia e os comunistas no Brasil. Rio de Janeiro: Graal, 1980.

LIMA, H. G. O ocaso do comunismo democrático: o PCB na última ilegalidade. 1995. Dissertação (Mestrado em Ciência Política) - Instituto de Filosofia e Ciências Humanas, Universidade Estadual de Campinas. Campinas, 1995.

MORAES, D. de. O imaginário vigiado: a imprensa comunista e o realismo socialista no Brasil (1947-1953). Rio de Janeiro: José Olympio, 1994.

MOTTA, R. A cultura política comunista: alguns apontamentos. In: MOTTA, R.; NAPOLITANO, M.; CZAJKA, R. Comunistas brasileiros: cultura política e produção cultural. Belo Horizonte: Editora UFMG, 2013. p.15-37.

MUZART, I.; ROLLAND, D. (Org.) L'exil brésilien en France: Histoire et imaginaire. Paris: L'Harmattan, 2008.

NAPOLITANO, M. Coração civil: arte, resistência e lutas culturais durante o regime militar brasileiro. 2011. Tese (Livre-Docência em História do Brasil Independente) Faculdade de Filosofia, Letras e Ciências Humanas, Universidade de São Paulo. São Paulo, 2011.

PRESTES, L. C. Carta aos comunistas. São Paulo: Alfa-Ômega, 1980.

RIDENTI, M. A brasilidade revolucionária. São Paulo: Editora Unesp, 2010.

ROLLEMBERG, D. Exilio: entre radares e raizes. Rio de Janeiro: Civilização Brasileira, 1999.

RUBIM, A. A. C. Partido Comunista, cultura e politica cultural. 1986. Tese (Doutorado em Sociologia) - Faculdade de Filosofia, Letras e Ciências Humanas, Universidade de São Paulo. São Paulo, 1986.

RUGAI, E.; FERNANDES, F. (Org.) Conversas com sociólogos brasileiros. São Paulo: Editora 34, 2006.

SILVA, E. P. Araucaria de Chile (1978-1990): a intelectualidade chilena no exílio. 2009. Dissertação (Mestrado em História Social) - Faculdade de Filosofia, Letras e Ciências Humanas, Universidade de São Paulo. São Paulo, 2009.

SILVEIRA, M. P. de L. Intelectuais comunistas e a questão democrática no Brasil. In: III SEMINÁRIO DISCENTE DA PÓS-GRADUAÇÃO EM CIÊNCIA POLÍTICA DA USP. Universidade de São Paulo, São Paulo, de 22 a 26 de abril de 2013.

TAFARELlO, P. M. Crise orgânica do Partido Comunista Brasileiro e o declínio do socialismo real. 2009. Dissertação (Mestrado em Ciências Sociais) - Faculdade de Filosofia e Ciências, Universidade Estadual Paulista "Júlio de Mesquita Filho". Marília, 2009.

VAIA, S. Armênio Guedes. Sereno guerreiro da liberdade. São Paulo: Barcarolla, 2013. 
VIANNA, L. W. Liberalismo e sindicato no Brasil. 4.ed. Belo Horizonte: Editora UFMG, 1999.

VV.AA. PCB: Vinte anos de politica (1958-1979). São Paulo: Livraria Editora Ciências Humanas, 1980.

RESUMO - Este artigo discute o novo protagonismo intelectual surgido na experiência do exílio de alguns militantes do Partido Comunista Brasileiro nos anos 1970, em diálogo com as diretrizes do eurocomunismo, com a questão nacional-popular e com o imperativo de resistir ao regime militar implantado em 1964. As "elaborações do exílio" do PCB, como ficaram conhecidas, foram importantes para fortalecer a estratégia frentista de resistência à ditadura, com implicações nas esferas política e cultural. Paradoxalmente, o frentismo entra em crise na medida em que a "abertura" se aprofunda e faz que os exilados retornem à cena política brasileira.

PALAVRAS-CHAVE: Partido Comunista Brasileiro: cultura e política, Intelectuais e resistência, Regime militar: resistência comunista.

ABSTRACT - This article discusses the new intellectual leadership emerged in the Brazilian Communist Party from the experience of exile in the 1970s. Many of the Brazilian intellectuals communists in Western Europe sustain a dialogue with the guidelines of Eurocommunism, with "national-popular question" and the resistance against the military regime implanted in 1964. The "elaborations of exile" of the PCB, as this process became known, were important to reinforce the strategy of front of democratic resistance to dictatorship, with implications in the political and cultural spheres. Paradoxically, the front strategy did not survive the context of "abertura", and the consequent return of the exiles to Brazil.

KEYWORDS: Brazilian Communist Party: culture and politics, Intellectuals and resistance, Military Regime: communist resistance.

Marcos Napolitano é doutor em História Social pela USP, professor do Departamento de História da Universidade de São Paulo, pesquisador-bolsista do CNPq, autor do livro 1964: história do regime militar brasileiro (Contexto, 2014). @ - napoli@usp.br

Recebido em 18.2.2014 e aceito em 28.2.2014.

${ }^{\text {I }}$ Faculdade de Filosofia, Letras e Ciências Humanas, Universidade de São Paulo, São Paulo/SP, Brasil. 